ORIGINAL ARTICLE

\title{
Intrinsic - Extrinsic - Transcendent. A triarchic model of goal contents: introduction and validation
}

\author{
Matgorzata Ewa Górnik-Durose $e^{A, B, C, D, E, F, G}$, Eukasz Jach $^{B, C, D, E, F}$, Marcin Langer ${ }^{D, E, F}$ \\ University of Silesia in Katowice, Poland
}

BACKGROUND

The article refers to an 11-factor circumplex model of goal contents introduced by Grouzet et al., which suggested a consistent structure of goals allocated within two dimensions: extrinsic-intrinsic and self-transcendent-physical. A previous study showed a rather poor fit of this model in a Polish context. Therefore using data from the aforementioned replication project in Study I we re-examined the structure and found a triarchic configuration more adequately fitting existing data. This new model was further tested in Study II.

\section{PARTICIPANTS AND PROCEDURE}

To find an adequate factor structure of life goals measured by the Polish version of the Aspiration Index in Study I we ran exploratory and confirmatory factor analyses in three groups of 1,762 people in total. To check psychometric characteristics of the developed $\mathrm{Al}-23$ questionnaire we conducted Study II on a group of 319 students.
RESULTS

The analyses revealed a new structure of the Aspiration Index consisting of scales related to seven life goals connected with three general groups of goals: intrinsic, extrinsic and transcendent. Results of confirmatory factor analysis, convergent and divergent validation, internal consistency and test-retest reliability allowed AI-23 to be treated as an effective tool to measure life goals.

\section{CONCLUSIONS}

The results suggest a triarchic organization of goal contents, with self-transcendent goals supplementing well-established theoretical categories of intrinsic and extrinsic goals.

\section{KEY WORDS}

Aspiration Index; Self-Determination Theory; intrinsic goals; extrinsic goals; self-transcendence

CORReSPONDING AUthor - Łukasz Jach, Ph.D., University of Silesia in Katowice, 53 Grażyńskiego Str., 40-126 Katowice,

Poland, e-mail: lukasz.jach@us.edu.pl

Authors' contribution - A: Study design · B: Data collection · C: Statistical analysis · D: Data interpretation ·

E: Manuscript preparation · F: Literature search · G: Funds collection

TO CITE THIS ARTICLE - Górnik-Durose, M. E., Jach, Ł., \& Langer, M. (2018). Intrinsic - Extrinsic - Transcendent.

A triarchic model of goal contents: introduction and validation. Current Issues in Personality Psychology, 6(1), 1-16.

RECEIVED 02.01.2017 · REVIEWED 03.02.2017 • ACCEPTED 06.02.2017 · PUBLISHED 14.04.2017 


\section{BACKGROUND}

Self-Determination Theory (SDT; Deci \& Ryan, 2007, 2008) assumes the presence of two types of motivation underlying human actions. Intrinsic motivation appears in spontaneous behaviors emerging from personal needs. Internally motivated activities are a source of positive emotions and stimulate personal development. Externally motivated activities are aimed at obtaining outcomes that are separable from the activities themselves. They are usually imposed and often unrelated to one's actual needs. Self-Determination Theory also draws a distinction between intrinsic and extrinsic goals, i.e. desired states, goods or values pursued by individuals (Kasser \& Ryan, 1993, 1996). Intrinsic goals, such as community feelings, health, personal growth and affiliation, are satisfying in their own right and provide direct gratification of basic psychological needs: autonomy, competence and relatedness. Extrinsic goals, on the other hand, manifest an external concept of worth rather than fulfillment of basic needs. Among them, money, image and fame are listed most often.

Studies attempting to pinpoint and identify psychological correlates, determinants and consequences of the aforementioned aspirations showed extrinsic and intrinsic goals as important factors regulating various day-to-day activities. For example, intrinsic aspirations were positively correlated with environmentally friendly behaviors (Brown \& Kasser, 2005); among people who tried to give up smoking, intrinsic aspirations regarding their physical health contributed to maintenance of abstinence from the subject of their addiction (Niemiec, Ryan, Deci, \& Williams, 2009). On the other hand, Sheldon and Kasser (2008) showed in a series of experiments that people who had induced insecurity had a higher level of aspiration associated with extrinsic targets. Consumer behavior and attitudes towards material goods are an important area of research conducted within the framework of SDT (Kasser, 2002). It has been observed, for example, that the aspirations related to personal development and addressing the needs of community and belonging impaired the willingness to make ostentatiously extravagant purchase decisions (Truong \& McColl, 2011). Research findings also revealed a relationship between aspirations and psychological well-being: greater well-being was observed among people oriented toward intrinsic goals than among people showing extrinsic aspirations (Kasser \& Ahuvia, 2002; Vansteenkiste, Duriez, Simons, \& Soenens, 2006).

The task of creating a fair, accurate and versatile questionnaire to study goal contents, rooted in SDT, was taken up by Grouzet and his co-workers (2005). Their starting point was a new version of the questionnaire referred to as the Aspiration Index and used for the first time in an inspiring study by Kasser and Ryan on the "dark side of the American dream" (Kasser \& Ryan, 1993, 1996). The 7-factor version of the Aspiration Index had been widely used over the years (e.g. Kasser \& Ahuvia, 2002; Kim, Kasser, \& Lee, 2003; Martos \& Kopp, 2012; Schmuck, Kasser, \& Ryan, 2000; Zawadzka, Duda, Rymkiewicz, \& Kondratowicz-Nowak, 2015). It referred to the following goals: personal development, affiliation, community feelings and health at the intrinsic end of the dimension, and financial success, proper image and popularity at the extrinsic end. Grouzet and his colleagues (2005) suspected that the seven-goal model might not represent a complete array of people's strivings in life. They proposed four additional goals, which were neither clearly intrinsic nor extrinsic in nature. These additional goals were conformity, safety, hedonism and spirituality. The latter was also previously taken into consideration by Kasser (1996).

The authors tested the 11-factor model in 15 different countries (the total sample consisted of 1,854 undergraduate students) and confirmed the presumed factor structure of the AI in the confirmatory factor analysis. The results showed that the model adequately fitted the data (RMSEA $=.045$, SRMR $=$ $.050)$. Grouzet and his co-workers also found support for the two-dimensional organization of the goal contents and for the hypothesis that the structure might be circular. The fit index RMSEA for the "circumplex" model was .065 (90\% CI: .058, .072) and was considered as indicating a close fit. One of the revealed dimensions of the structure extended from intrinsic to extrinsic aspirations, the second from self-transcendence to physical self. The goals were located on the circumference in the following sequence: spirituality and community feeling (in the quarter defined by self-transcendence and intrinsic ends of the two dimensions), affiliation, self-acceptance, physical health, safety and hedonism (intrinsic - physical self quarter), financial success, image and popularity (physical self - extrinsic quarter), and conformity (extrinsic - self-transcendence quarter).

Although since its publication in 2005 the article has been cited over 471 times (according to Google Scholar from $21^{\text {st }}$ September 2016), the model had not been compared with data other than the original sets in any replication study. Hence the circumplex model of goal contents and the psychometric properties of the 11-factor Aspiration Index were verified by Górnik-Durose and Jach (2016) in a different cultural context.

The aforementioned study combined data from nine Polish samples (in sum 1,762 mainly university students). The procedure strictly followed steps taken in the original study. The results did not explicitly confirm those obtained by Grouzet and his colleagues (2005; for details: see Górnik-Durose \& Jach, 2016). Internal consistency was the first problematic issue of some subscales from the Aspiration Index. 
Furthermore, CFA conducted to confirm the 11-factor structure of the goal contents in Polish samples showed rather poor fits in all samples. Relatively the best fit indices were obtained in an aggregated sample of 1,762 participants (RMSEA $=.066$, SRMR $=$ .087); hence further analyses were conducted on data from that sample, mainly to take advantage of the substantial number of subjects. Although the results of the multidimensional scaling generally supported the assumption about the two-dimensional goal contents structure, an ipsative distance analysis reproduced only the extrinsic-intrinsic dimension. An alternative analysis revealed a different configuration of goals, signified by conflicts in a triangle: spirituality - intrinsic goals (community feeling/self acceptance/affiliation/health/ safety/hedonism) - extrinsic goals (money/popularity/image/conformity). Finally, although the CIRCUM analysis showed that the organization of goal contents on the circumference was quite similar to that described by Grouzet et al., the RMSEA indicated poor fit (.099; 90\% CI: .092, .106).

\section{IN SEARCH OF A DIFFERENT SOLUTION}

The ipsative distance analysis conducted in the replication study confirmed the strength of the intrinsic-extrinsic dimension in the goal content model. It also showed that these basic categories were supplemented by a salient category related to the spiritual aspects of human aspirations.

Spirituality (or self-transcendence in broader terms) is far beyond the intrinsic tendencies to fulfill self-centered psychological needs, and also beyond the orientation on extrinsically regulated material aspects of life. It belongs to a separate domain, which should not be excluded from any comprehensible description and explanation of human goals and aspirations.

Grouzet and his colleagues (2005) defined spirituality as the utmost self-transcendent goal, neither intrinsic or extrinsic, positioned in relatively close proximity to two other goals - more extrinsic conformity and more intrinsic community feelings, and opposite to a hedonic goal of bodily pleasures, safety and physical health. They based their definition of spirituality as a goal on a theoretical explanation laid down by Emmons (1999, 2005; Emmons, Cheung, \& Tehrani, 1998), who acknowledged that spiritual strivings could be extended beyond religion. Although recognized as a need to seek out universal meanings and understandings, spirituality was still considered as a goal very similar to religiousness, as it could be pursued to acquire intrinsic satisfaction from communion with one's church or to avoid fears of punishment and guilt, which are extrinsic in nature. Such conceptualization of spirituality might be seen as problematic and not entirely accurate.
The understanding of spirituality as a goal similar to and interchangeable with religion ignores the historically ever-growing category of people associating themselves as "spiritual, not religious" (Comte-Sponville, 2009; Schmidt, 2005). Studies on secular people valuing spirituality confirm that spirituality does not equal religion, e.g. Ecklund and Long's (2011) study on the views of 275 scientists showed that they formed some sort of "spiritual atheism" as a result of understanding their spiritual beliefs to be closely related to science and its pursuit of truth rather than to religion.

The somewhat problematic and virtually non-existent opposition between spirituality and physical self, especially hedonism, as noted in the study by Górnik-Durose and Jach (2016), could probably originate in this religious definition of spirituality. From a religious perspective, hedonistic pleasures are "sinful" and clearly a distraction undermining the pursuit of transcendental goals placed in a mystical relation with the non-material, a pursuit which ultimately would lead to pure asceticism and disregard of the material world (Comte-Sponville, 2009). In contrast, secular definitions of spirituality embrace hedonistic pleasures as one of many significant ways of showing love of this life and the world, as long as they are not vulgarized into pathological devotion to sex, luxuries, money and fame, and involve a larger sense of life, leading to a transformation of the self beyond selfishness (Comte-Sponville, 2009; Solomon, 2002). This distinction potentially explains not only why spirituality should not be seen as completely antagonistic to hedonism with no middle ground, but ultimately could provide a working hypothesis as to why spirituality as a goal could be still highly valued in today's rather secular world.

Thus, the three domains of goals - intrinsic, extrinsic and spiritual (transcendent) - were implemented into a new model. In Study I we aimed to find evidence for such a model as well as to create a measurement tool which would enable testing of that model suitably and accurately. Study II was aimed mainly at validation of the new version of the Aspiration Index.

\section{STUDY I}

\section{BACKGROUND}

The objective of Study I was to reanalyze data used previously by Górnik-Durose and Jach (2016) to verify the 11-factor circumplex model of goal contents, introduced by Grouzet and his colleagues (2005). The first step involved the reexamination of the latent structure of goal contents in exploratory factor analyses (EFA). It was anticipated that three assumed higher-order categories of goals - intrinsic, extrinsic and spiritual - would be revealed as a result of 
such an investigation. If that would be the case, we planned to test the alternative configuration in confirmatory factor analyses (CFA).

It has to be noted that we returned to the previous conceptualization of goal contents by Kasser and Ryan (1993, 1996); therefore we took into account goals included in intrinsic and extrinsic domains. Following the results of the Polish replication, we added goals from the spiritual domain. We excluded goals which were added ad hoc by Grouzet and his collaborators (2005) because the theoretical and empirical validity of that category appeared to be questionable (see Górnik-Durose \& Jach, 2016).

\section{PARTICIPANTS AND PROCEDURE}

A Polish version of the Aspiration Index with all 57 items was used (cf. Górnik-Durose \& Janiec, 2010; Górnik-Durose \& Jach, 2016). Subjects were giving answers on a 5-point scale as in the original measure used by Kasser and Ryan (1993) in their first study on aspirations, instead of the 9-point scale reported by Grouzet et al. (2005).

The AI-PL was applied in nine separate research projects over 5 years (2009-2013). In total 1,762 subjects participated in these studies. Mean age of participants ranged from 22.08 to 31.23 , and women constituted $37.00-73.60 \%$ of the consecutive samples.

The questionnaire was distributed among participants at universities, workplaces and activity centers. They were asked to state how important each goal was to them on a scale from 1 (not at all) to 5 (very important). In all cases the AI-PL was included in larger survey packets. No incentives were provided to the subjects in exchange for their participation.

Statistical analyses were conducted in LISREL 9.2, Statistica 10 and IBM SPSS Statistics 22.

\section{RESULTS}

Step I: In the quest for a "tailored" model exploratory factor analyses

The goal contents were reexamined in exploratory factor analyses (EFA) run first without any initial assumptions regarding latent structure, and afterwards assuming a 3-factor solution. The EFA was run on one of the nine samples, marked as Sample A ( $N=528$; mean age $22.08,66.10 \%$ of women). The Kaiser-Meyer-Olkin (K-M-O) measure of sampling adequacy was .88 , and Bartlett's test of sphericity was significant $\left(\chi^{2}(630)=9079.26, p<.001\right)$. Principle components analysis and Varimax rotation with Kaiser's normalization were applied.

The three factors explained $43.29 \%$ of variance. The first factor (22.25\% of variance explained) consisted of items which originally created money, image and popularity subscales, with an additional single item from the affiliation subscale. Without the "wandering" item this factor reproduced fully the extrinsic cluster of life goals. The second factor $(13.41 \%$ of variance explained) grouped items from self-acceptance, affiliation and health subscales with an additional single item from the spirituality subscale. Without the "wandering" item this factor reflected the intrinsic cluster, exclusive of the community feeling subscale. The third factor ( $7.63 \%$ of variance explained) joined together items from the original community and spirituality subscales with the single addition of an item from the self-acceptance subscale. Without the "wanderer" it formed a salient transcendent cluster. Thus, the EFA reproduced the assumed three-cluster structure of goal contents. Factor loadings for the 3-factor solutions without "wandering" items no. 8, 46 and 49 are shown in Table 1 column EFA I (K-M-O for the corrected model was .87, and Bartlett's test of sphericity was significant $-\chi^{2}(528)=8207.63$, $p<.001 ; 44.47 \%$ of variance was explained).

Items which created the three factors - extrinsic, intrinsic and transcendent - were further analyzed in three separate principle components analyses using Varimax rotation with Kaiser's normalization. No initial assumption regarding a number of factors was made. The three "wandering" items were removed from the analyses on the basis of their questionable validity as indicators of particular clusters of goals.

Within the extrinsic domain $\left(\mathrm{K}-\mathrm{M}-\mathrm{O}=.895, \chi^{2}(66)\right.$ $=2825.72, p<.001)$ two factors were identified, explaining together $56.62 \%$ of variance. The first factor related plainly to the financial success subscale, while the second merged items from image and popularity. Within the intrinsic domain $(\mathrm{K}-\mathrm{M}-\mathrm{O}=.837$, $\left.\chi^{2}(91)=2534.83, p<.001\right)$ three factors emerged $(55.94 \%$ of variance explained). The first one consisted of items from the self-acceptance subscale, the second consisted of the affiliation subscale, and the third brought together items from the physical health subscale. The transcendent cluster $\left(\mathrm{K}-\mathrm{M}-\mathrm{O}=.817, \chi^{2}(21)\right.$ $=1818.58, p<.001,72.66 \%$ of variance explained) $\mathrm{was}$ divided clearly between spirituality and community feelings. The factor loadings are shown in Table 1 column EFA I.

The revealed structure was also identified in results of EFA conducted on all items (excluding "wanderers"), which clearly showed 7 factors explaining $62.14 \%$ of variance $\left(\mathrm{K}-\mathrm{M}-\mathrm{O}=.874, \chi^{2}(528)=8267.64\right.$, $p<.001)$. The factor loading are presented in Table 1.

In the next step all items were examined from the point of view of their potential usefulness to reflect adequately the goal structure in a measurement instrument, i.e. a revised Aspiration Index. The items chosen for the instrument are in bold letters in Table 1. The criteria were as follows: (a) an item had to load only on one factor, (b) in both EFA - on items within three domains of goals, intrinsic, extrinsic and spir- 
Table 1

Results of EFA in Study I (Sample A)

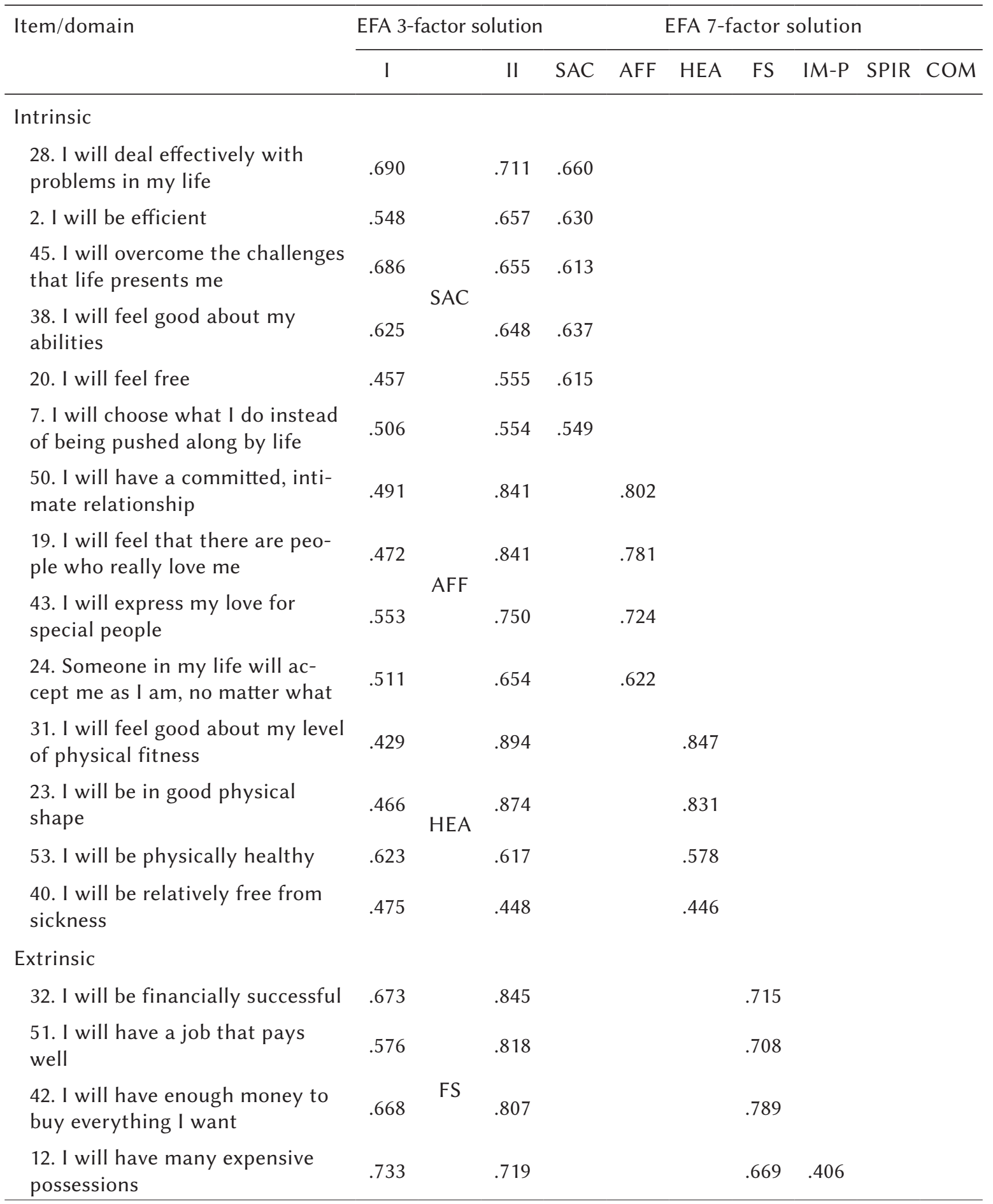

(Table 1 continues) 
Table 1

(Table 1 continued)

\begin{tabular}{|c|c|c|c|c|c|c|c|c|c|c|}
\hline \multirow[t]{2}{*}{ Item/domain } & \multicolumn{5}{|c|}{ EFA 3-factor solution } & \multicolumn{5}{|c|}{ EFA 7-factor solution } \\
\hline & I & & II & SAC & AFF & HEA & FS & IM-P & SPIR & $\mathrm{COM}$ \\
\hline $\begin{array}{l}\text { 30. People will often comment } \\
\text { about how attractive I look }\end{array}$ & .724 & & .808 & & & & & .758 & & \\
\hline $\begin{array}{l}\text { 3. My image will be one others } \\
\text { find appealing }\end{array}$ & .640 & & .753 & & & & & .735 & & \\
\hline $\begin{array}{l}\text { 14. I will be admired by many } \\
\text { people }\end{array}$ & .749 & & .634 & & & & & .733 & & \\
\hline $\begin{array}{l}\text { 37. Almost everyone who knows } \\
\text { me will like me }\end{array}$ & .488 & & .686 & & & & & .514 & & \\
\hline $\begin{array}{l}\text { 39. I will successfully hide the } \\
\text { signs of aging }\end{array}$ & .642 & $1 / N 1 / P$ & .548 & & & & .503 & .416 & & \\
\hline $\begin{array}{l}\text { 13. I will achieve the "look" I've } \\
\text { been after }\end{array}$ & .569 & & .515 & & & & & .531 & & \\
\hline $\begin{array}{l}\text { 55. I will keep up with fashions } \\
\text { in clothing and hair }\end{array}$ & .685 & & .502 & & & & .535 & .442 & & \\
\hline $\begin{array}{l}\text { 22. My name will be known by } \\
\text { many different people }\end{array}$ & .609 & & .432 & & & & .404 & .504 & & \\
\hline \multicolumn{11}{|l|}{ Transcendent } \\
\hline $\begin{array}{l}\text { 36. I will find religious or spiri- } \\
\text { tual beliefs that help me make } \\
\text { sense of the world }\end{array}$ & .827 & & .910 & & & & & & .908 & \\
\hline $\begin{array}{l}\text { 44. I will find religious and/ } \\
\text { or spiritual beliefs that are } \\
\text { growth-producing }\end{array}$ & .826 & SPIR & .902 & & & & & & .903 & \\
\hline $\begin{array}{l}\text { 26. I will find satisfying religious } \\
\text { and/or spiritual activities }\end{array}$ & .794 & & .767 & & & & & & .766 & \\
\hline $\begin{array}{l}\text { 4. I will find personal answers to } \\
\text { universal spiritual questions }\end{array}$ & 699 & & .759 & & & & & & .759 & \\
\hline $\begin{array}{l}\text { 21. The things I do will make } \\
\text { other people's lives better }\end{array}$ & .487 & & .873 & & & & & & & .765 \\
\hline $\begin{array}{l}\text { 6. I will assist people who need it, } \\
\text { asking nothing in return }\end{array}$ & .502 & $\mathrm{COM}$ & .857 & & & & & & & .780 \\
\hline $\begin{array}{l}\text { 47. I will help the world become } \\
\text { a better place }\end{array}$ & .627 & & .721 & & & & & & & .681 \\
\hline
\end{tabular}

Note. SAC - self-acceptance; AFF - affiliation; HEA - health; FS - financial success; IM/P - image/popularity; SPIR - spirituality; COM - community feeling.

itual, and on all items together, factor loadings had to be greater than 0.6 (values meeting this criterion are marked bold in Table 2). The final version of the revised instrument (AI-23) consisted of 23 items: four in self-acceptance, affiliation and spirituality subscales, three in financial success, image/popularity and community subscales, and two in the health subscale. In comparison to the AI used by Grouzet et al. (2005), not only conformity, safety and hedonism subscales were removed, but also most of the subscales were shortened: self-acceptance from 8 to 4 items, affiliation and spirituality from 5 to 4 items, health from 4 to 2 items, financial success from 4 to 3 items. Original image and popularity subscales were joined together and reduced to 3 items (from 8 ).

The internal consistency of seven new subscales as well as of three identified domains of goals was assessed using Cronbach's $\alpha$ coefficient in all nine samples. Table 2 shows a summary of results of these analyses. All tested scales and domains showed good 
Table 2

Internal consistency (Cronbach's $\alpha$ ) of 7 subscales and 3 domains of goals in Al-23 - summary of results from 9 samples

\begin{tabular}{|c|c|c|c|c|c|c|c|}
\hline Subscale & SAC & AFF & HEA & $\mathrm{FS}$ & $\mathrm{IM} / \mathrm{P}$ & SPIR & $\mathrm{COM}$ \\
\hline No. of items & 4 & 4 & 2 & 3 & 3 & 4 & 3 \\
\hline Mean & .74 & .78 & .82 & .83 & .75 & .81 & .75 \\
\hline Median & .74 & .78 & .86 & .79 & .74 & .81 & .76 \\
\hline $\min$ & .65 & .67 & .67 & .74 & .67 & .78 & .68 \\
\hline $\max$ & .83 & .85 & .92 & .88 & .82 & .86 & .85 \\
\hline Domain & \multicolumn{3}{|c|}{ Intrinsic } & \multicolumn{2}{|c|}{ Extrinsic } & \multicolumn{2}{|c|}{ Transcendent } \\
\hline No. of items & \multicolumn{3}{|c|}{10} & \multicolumn{2}{|c|}{6} & \multicolumn{2}{|c|}{7} \\
\hline Mean & \multicolumn{3}{|c|}{.80} & \multicolumn{2}{|c|}{.80} & \multicolumn{2}{|c|}{.84} \\
\hline Median & \multicolumn{3}{|c|}{.81} & \multicolumn{2}{|c|}{.81} & \multicolumn{2}{|c|}{.84} \\
\hline $\min$ & \multicolumn{3}{|c|}{.72} & \multicolumn{2}{|c|}{.72} & \multicolumn{2}{|c|}{.81} \\
\hline $\max$ & \multicolumn{3}{|c|}{.90} & \multicolumn{2}{|c|}{.84} & \multicolumn{2}{|c|}{.88} \\
\hline
\end{tabular}

Note. SAC - self-acceptance; AFF - affiliation; HEA - health; FS - financial success; IM/P - image/popularity; SPIR - spirituality; COM - community feelings.

internal consistency. The Cronbach's $\alpha$ values in most of the samples exceeded .70 .

Therefore it is justified to claim that as a result of EFA a three-domain seven-factor structure was identified which matched the assumption about a triarchic goal structure. The analyses reproduced fully the intrinsic-extrinsic distinction identified on the basis of SDT and gave strong support for the assumed existence of an additional category of transcendent goals which included striving for meaning in life (spirituality) and attempts to make the world a better place for everyone (community feelings).

Step II: Confirming the 7-factor triarchic model (CFA results)

The second step of re-analyzing data obtained from Polish samples was verification of the new model in CFA. They were run on the remaining data from which two samples (B and C) were extracted. Each sample consisted of 617 subjects. Two models were tested in each sample - a straight 7-factor model, and a hierarchical model with three higher-order factors. The models were evaluated simultaneously with multiple fit indices such as: $\chi^{2} / d f$ (based on Satorra-Bentler scaled $\chi^{2}$ ), root mean square error of approximation (RMSEA) and its associated confidence interval, standardized root mean square residual (SRMR), comparative fit index (CFI) and non-normed fit index (NNFI). The relevant fit indices are presented in Table 3.

Taking into consideration Hu and Bentler's (1999) decision rules for the goodness of fit for complex models and "rules of thumb" listed by SchermellehEngel, Moosbrugger, and Müller (2003), it has to be stated that the criteria of at least acceptable, but mainly good fit, were met in both samples in relation

Table 3

Results of CFA in Study I and Study II - fit indices

\begin{tabular}{|c|c|c|c|c|c|c|c|}
\hline Sample & $N$ & Model & $\chi^{2^{*}} / d f$ & RMSEA $(90 \% \mathrm{CI})$ & SRMR & CFI & NNFI \\
\hline \multicolumn{8}{|l|}{ Study I } \\
\hline \multirow{2}{*}{ Sample B } & \multirow{2}{*}{617} & 7-factor & 2.46 & $.049(.043, .054)$ & .050 & .97 & .97 \\
\hline & & hierarchical & 2.77 & $.054(.049, .0 .59)$ & .073 & .97 & .96 \\
\hline \multirow{2}{*}{ Sample C } & \multirow{2}{*}{617} & 7-factor & 2.04 & $.041(.036, .047)$ & .049 & .97 & .97 \\
\hline & & hierarchical & 2.27 & $.045(.040, .051)$ & .063 & .97 & .96 \\
\hline \multicolumn{8}{|l|}{ Study II } \\
\hline \multirow{2}{*}{ Sample D } & \multirow{2}{*}{319} & 7-factor & 1.54 & $.041(.032, .050)$ & .047 & .98 & .98 \\
\hline & & hierarchical & 1.65 & $.045(.032, .053)$ & .063 & .98 & .97 \\
\hline
\end{tabular}

Note. ${ }^{*}$ Satorra-Bentler scaled $\chi^{2}$. 
to both models. They were only slightly better for the straight 7-factor model than the hierarchical model. All items loaded significantly on their respective factor (see Table 4), and all standardized regression weights were greater than .40 (a criterion suggested by Brown, 2006). The mean correlation for the
7 latent factors in Samples B and C were .28 and .24 respectively. However, they were much higher within three domains than between factors belonging to different domains: .52 and .59 for the self-transcendence domain, .48 and .38 for the intrinsic domain and .62 and .54 for the extrinsic domain, whereas the

Table 4

Standardized regression weights - a summary of results from 4 samples

\begin{tabular}{|c|c|c|c|c|}
\hline \multirow[t]{2}{*}{ Item No. } & \multirow[t]{2}{*}{ Subscale } & \multicolumn{2}{|c|}{ Study I } & \multirow{2}{*}{$\begin{array}{l}\text { Study II } \\
\text { Group D }\end{array}$} \\
\hline & & Group B & Group C & \\
\hline 2 & SAC & 0.68 & 0.45 & 0.62 \\
\hline 28 & SAC & 0.71 & 0.64 & 0.70 \\
\hline 38 & SAC & 0.67 & 0.62 & 0.64 \\
\hline 45 & SAC & 0.65 & 0.72 & 0.79 \\
\hline 19 & AFF & 0.84 & 0.72 & 0.74 \\
\hline 24 & AFF & 0.68 & 0.48 & 0.49 \\
\hline 43 & AFF & 0.68 & 0.68 & 0.75 \\
\hline 50 & AFF & 0.80 & 0.70 & 0.71 \\
\hline 23 & HEA & 0.95 & 0.80 & 0.90 \\
\hline 31 & HEA & 0.77 & 0.89 & 0.80 \\
\hline 42 & FS & 0.69 & 0.65 & 0.75 \\
\hline 32 & $\mathrm{FS}$ & 0.82 & 0.84 & 0.88 \\
\hline 51 & $\mathrm{FS}$ & 0.75 & 0.67 & 0.80 \\
\hline 30 & $\mathrm{IM} / \mathrm{P}$ & 0.77 & 0.73 & 0.88 \\
\hline 14 & $\mathrm{IM} / \mathrm{P}$ & 0.69 & 0.66 & 0.74 \\
\hline 3 & $\mathrm{IM} / \mathrm{P}$ & 0.72 & 0.69 & 0.73 \\
\hline 4 & SPIR & 0.66 & 0.67 & 0.64 \\
\hline 26 & SPIR & 0.73 & 0.84 & 0.78 \\
\hline 36 & SPIR & 0.87 & 0.87 & 0.89 \\
\hline 44 & SPIR & 0.87 & 0.85 & 0.91 \\
\hline 6 & $\mathrm{COM}$ & 0.73 & 0.66 & 0.77 \\
\hline 21 & $\mathrm{COM}$ & 0.80 & 0.74 & 0.84 \\
\hline 47 & $\mathrm{COM}$ & 0.68 & 0.68 & 0.79 \\
\hline Subscale & Domain & & & \\
\hline SPIR & TRANS & 0.55 & 0.58 & 0.60 \\
\hline $\mathrm{COM}$ & TRANS & 0.95 & 1.01 & 0.82 \\
\hline SAC & INT & 0.89 & 0.73 & 0.71 \\
\hline AFF & INT & 0.66 & 0.64 & 0.63 \\
\hline HEA & INT & 0.55 & 0.49 & 0.52 \\
\hline FS & EXT & 1.01 & 1.07 & 0.85 \\
\hline $\mathrm{IM} / \mathrm{P}$ & EXT & 0.62 & 0.51 & 0.68 \\
\hline
\end{tabular}

Note. SAC - self-acceptance; AFF - affiliation; HEA - health; FS - financial success; IM/P - image/popularity; SPIR - spirituality; COM - community feelings. 
mean correlations between factors belonging to different domains were as follows: for self-transcendent and intrinsic .28 and .26, for self-transcendent and extrinsic -.06 and -.07 , for intrinsic and extrinsic .30 and .24 .

\section{CONCLUSIONS}

In Study I we re-examined data collected with the Polish version of the 11-factor Aspiration Index (Grouzet et al., 2005). The detailed reanalysis of the data with EFA revealed seven factors fully built into three domains of goals. Intrinsic goals incorporated strivings related to self-acceptance, affiliation and health. Extrinsic goals included financial success and a factor joining together image and popularity which reflected striving for a proper image in order to receive admiration from other people. Transcendent goals integrated strivings for spiritual understanding of meaning of life and attempts to make the world a better place for everyone. Such structure was proved in confirmatory factor analyses. EFA and CFA results also showed which items from the Aspiration Index adequately reflected the new structure of goal contents.

\section{STUDY II}

\section{BACKGROUND}

In Study II we examined the psychometric properties of the new Aspiration Index (AI-23) - the internal consistency of the 7 subscales and 3 domains, as well as their stability over time. We also looked at convergent and divergent validity of the AI-23 with respect to the refined value structure proposed by Schwartz et al. (2012). Taking into consideration the importance of the category of transcendent goals for the AI-23, we compared it furthermore with an additional concept of spirituality, proposed by Heszen-Niejodek and Gruszczyńska (2004).

Although there is a conceptual difference between values and goals, both motivational forces are often associated. Goals are strivings, personal projects, and aspirations that people pursue, and the examination of their contents is seen "as a way of understanding how people organize their lives and the types of aims for which individuals strive" (Grouzet et al., 2005, p. 801); on the other hand, values - according to Schwartz (1992) - are trans-situational goals that are guiding principles in the lives of individuals or groups. Thus, an attempt to check the validity of the goal contents structure against the well-established and empirically verified value structure seems to be justified. Taking into consideration the nature of goals and values we did not expect that certain goals would correspond one-to-one to certain values. Rather we expected that certain domains of individual values would be reflected in goals of a certain nature. Hence we formed the following assumptions:

A. Self-acceptance pursuits would arise from valuing freedom to cultivate one's own ideas and take up one's own actions; in addition, if the achievement value could be understood as a desire to confirm publicly one's capabilities (see Schwartz et al., 2012), self-acceptance might be positively correlated with that value.

B. Health as a goal would be expected to connect with the personal security value; however, in the value structure its position is not stable - the location of health was inconsistent across different studies (Schwartz et al., 2012). We assumed then that there is more in health as a goal and value than just a security expectation. Health could be understood as an assurance of one's own effectiveness in achieving independently other important life aspirations and being free from pain and anxiety (Górnik-Durose, Jach, Sikora, \& Wojtyna, 2013); thus the pursuit of health would be based more on the values from the openness to change spectrum (from self-direction to hedonism) than conservation and security.

C. Affiliation could be seen as a bridge between concentration on self and on others. Achieving that goal satisfies the inherent need for belonging, but at the same time requires engagement in all sorts of social relationships and structures; thus we expected that affiliation would be connected with the whole spectrum of values that are socially focused - from security to universalism and benevolence.

D. Striving for financial success, proper image and popularity were usually ascribed to self-enhancement values (cf. Kilbourne, Grunhagen, \& Foley, 2005; also Schwartz et al., 2012); we retained this assumption, expecting hedonism, achievement and power to correlate positively with financial success and image/popularity goals. Also we assumed that because these goals are connected with striving to avoid or cope with anxiety (see Kasser, 2002) they would be connected with valuing security, especially personal.

E. Spirituality and community were assumed to connect mainly with self-transcendence values, but also with other values from the conservation spectrum (societal security, tradition, conformity and humility), because of their relations to religion, which to some extent gives a form to spirituality (Emmons, 1999), and also to connect with other social virtues, included implicitly in listed values, that are promoted simultaneously within various forms of spirituality as well as community involvement, e.g. self-discipline, respect for others, avoidance of upsetting or harming people, not 
drawing attention to oneself, being obedient, and not asking for too much (Schwartz et al., 2012). We also assumed that transcendent goals would be negatively related to self-enhancement values.

Regarding the external spirituality indicators, we expected a positive correlation between the transcendent goals and all three aspects of spirituality described by Heszen-Niejodek and Gruszczyńska (2004) - religiosity, aesthetic sensitivity and harmony.

\section{PARTICIPANTS AND PROCEDURE}

The new version of the Aspiration Index (AI-23), which consisted of 23 items grouped in 7 subscales, was used. Subjects were asked to state how important each goal was to them on a scale from 1 (not at all) to 5 (very important). In order to examine the value structure we used the Portrait Values Questionnaire (PVQ-R3) in the Polish adaptation by Cieciuch (2013). The third questionnaire was an instrument developed by Heszen, Gruszczyńska and Metlak (Heszen-Niejodek \& Gruszczyńska, 2004) to measure spirituality in three aspects identified by the authors - religiosity, aesthetic sensitivity and harmony.

The participants were students from the University of Silesia in Katowice (Sample D). There were 319 participants in the first phase of data collection ("test"), of whom $66.30 \%$ were women. In the second phase ("retest") only 79 participants took part, of whom $73.40 \%$ were women. The mean age of subjects was 21.60 .

The questionnaires were distributed in the paper form among students. No incentives were provided to the subjects in exchange for their participation. The participants were asked to fill in the AI-23 twice - in the test and retest phase (three to four weeks after the first data collection).

Statistical analyses were conducted in LISREL 9.2, Statistica 10 and IBM SPSS Statistics 22.

\section{RESULTS}

\section{The reliability of the AI-23}

A summary of parameters describing the psychometric properties of the AI-23 is presented in Table 5 .

The reliability analysis of the AI-23 was based on Cronbach's $\alpha$ test-retest correlations and correlations between the latent variable and the observed variables (IoQ). All but one item evidenced acceptable IoQ (based on the criterion of .30 recommended by Nunnally \& Bernstein, 1994). The lowest values were identified in relation to items from the self-acceptance scale. Also all but one scale demonstrated adequate internal consistency and stability. Only the self-acceptance subscale had a relatively low reli- ability in the retest condition (Cronbach's $\alpha=.59$ ). It was also reflected in relatively weak reliability of the intrinsic domain in the retest condition (Cronbach's $\alpha=.65$ ) and weaker test-retest correlations (.56 for the self-acceptance subscale, .68 for the intrinsic domain). The rest of the subscales showed good stability and consistency.

\section{The factor structure of the AI-23}

In the next step we tested the factor structure of the AI-23 in CFA. As in Study I two models were tested - the 7-factor model, and the hierarchical model with three higher-order factors and seven first-order factors, as previously described. The results are presented in Table 3 in the part related to Study II and Sample D.

The indices indicated a definitely good fit of both models, taking into consideration $\mathrm{Hu}$ and Bentler's (1999) decision rules and "rules of thumb" listed by Schermelleh-Engel, Moosbrugger and Müller (2003). All items loaded significantly on their respective factor (see Table 4), and all standardized regression weights were greater than .40 .

\section{The convergent and divergent validity of the AI-23}

The validity of the AI-23 was examined through zero-order Pearson correlations of subscale scores and indicators of values in Schwartz's model as well as indicators of spirituality. Table 6 presents correlations between seven types of goals and nineteen values listed recently by Schwartz et al. (2012). At the bottom of the table the correlations between goals and spirituality in its three aspects are also displayed.

Most of the assumed correlations were confirmed. Self-acceptance goals correlated positively with self-direction and achievement values, health correlated with values indicating openness to change rather than security, and affiliation correlated with socially focused values. The concentration on financial success and image/popularity reflected the self-enhancement values. Transcendent goals appeared to be positively correlated with self-transcendent and negatively with self-enhancement values. Finally, the goals of spirituality and community feelings correlated strongly - as expected - with external indicators of spirituality.

Table 6 also shows some other correlations that were not assumed, such as a positive correlation of self-acceptance and affiliation with the face value, and the connection of self-direction values with extrinsic and transcendent goals. Although unexpected, they seemed to support the validity of the extracted goals.

Face relates to maintaining and protecting prestige, and achieving social recognition and respect (Schwartz et al., 2012). Although it was considered to be a power value subtype, it would also be inter- 


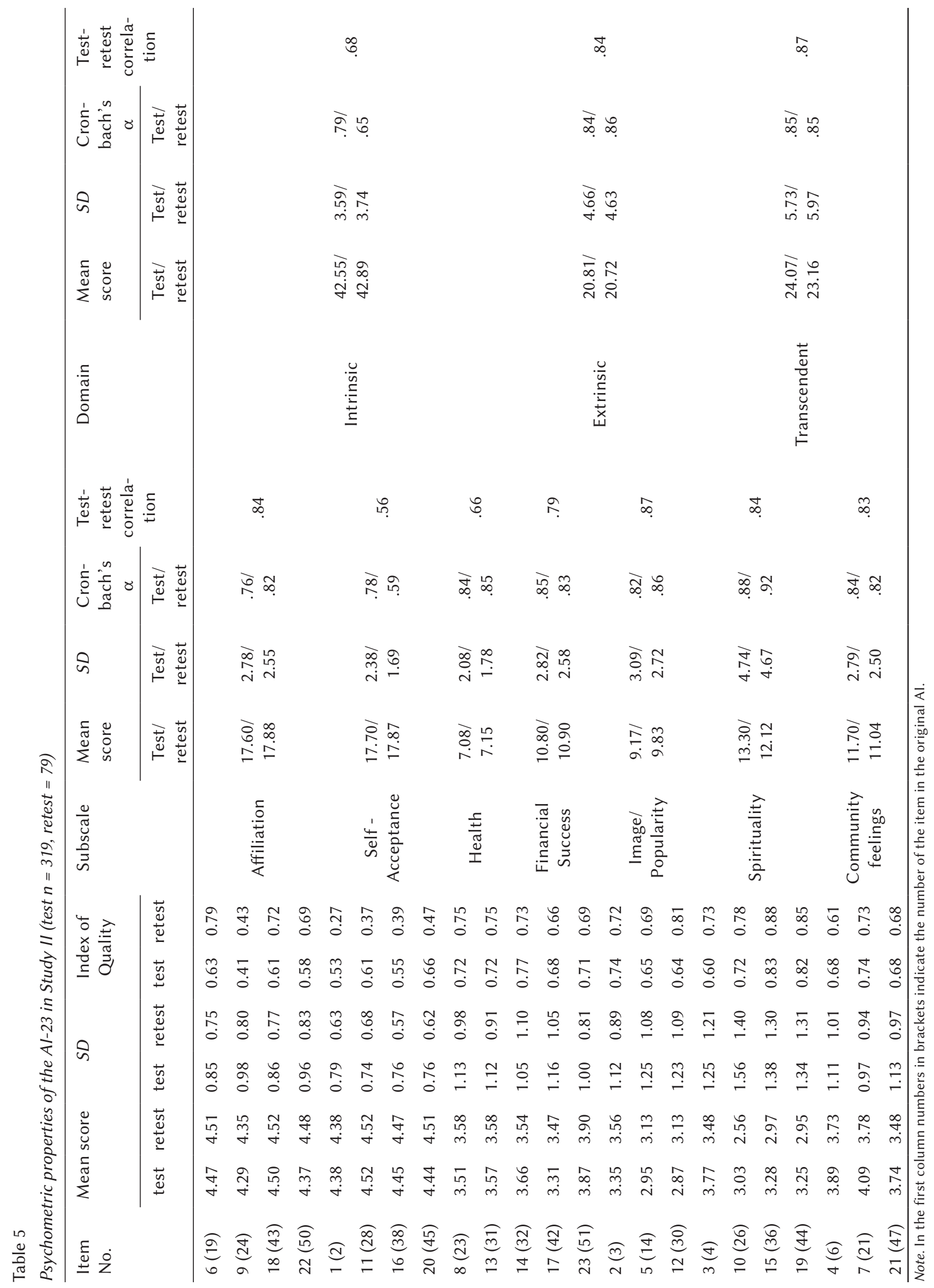


Table 6

Pearson's correlation between goals, values and external spirituality indicators

\begin{tabular}{|c|c|c|c|c|c|c|c|}
\hline Values & SAC & AFF & HEA & FS & $\mathrm{IM} / \mathrm{P}$ & SPIR & $\mathrm{COM}$ \\
\hline SDT & $.280^{* *}$ & -.004 & $.273^{*}$ & .094 & -.004 & $.202^{*}$ & $.247^{* *}$ \\
\hline SDA & $.440^{* *}$ & -.050 & $.223^{*}$ & $.230^{*}$ & -.053 & -.048 & -.089 \\
\hline $\mathrm{ST}$ & .122 & -.069 & $.365^{* *}$ & $.219^{*}$ & .110 & .087 & .067 \\
\hline $\mathrm{HE}$ & .136 & .147 & $.271^{* *}$ & $.324^{* *}$ & $.250^{* *}$ & .049 & -.080 \\
\hline$A C$ & $.235^{*}$ & $.232^{*}$ & -.038 & $.471^{* *}$ & $.563^{*}$ & -.160 & -.021 \\
\hline POD & .137 & $-.215^{*}$ & .073 & $.236^{*}$ & $.229^{*}$ & $-.181^{+}$ & .139 \\
\hline POR & .013 & .087 & .135 & $.771^{* *}$ & $.582^{* *}$ & $-.191^{*}$ & $-.197^{*}$ \\
\hline FAC & $.212^{*}$ & $.191^{*}$ & -.082 & $.361^{* *}$ & $.553^{* *}$ & $-.224^{*}$ & -.076 \\
\hline SEP & .107 & $.338^{* *}$ & -.005 & $.254^{*}$ & $.333^{* *}$ & -.014 & -.047 \\
\hline SES & .162 & .093 & .152 & .059 & .057 & $.306^{* *}$ & $.374^{* *}$ \\
\hline TR & .018 & $.344^{* *}$ & .054 & .103 & $.230^{*}$ & $.364^{* *}$ & $.533^{* *}$ \\
\hline COR & .128 & $.228^{*}$ & -.055 & .135 & .159 & $.230^{*}$ & .140 \\
\hline $\mathrm{COI}$ & -.179 & $.361^{* *}$ & -.031 & .009 & .173 & $.316^{* *}$ & .156 \\
\hline $\mathrm{HU}$ & -.012 & $.269^{* *}$ & -.050 & -.124 & -.166 & $.295^{* *}$ & .072 \\
\hline BEC & .024 & $.590^{* *}$ & -.009 & .103 & .140 & $.546^{* *}$ & .117 \\
\hline BED & .088 & $.581^{* *}$ & -.017 & .168 & $.240^{*}$ & $.456^{* *}$ & $.205^{*}$ \\
\hline UNC & -.072 & $.329^{* *}$ & -.037 & -.095 & .026 & $.560^{* *}$ & $.219^{*}$ \\
\hline UNN & .019 & $.315^{* *}$ & .051 & -.122 & -.130 & $.281^{* *}$ & $.196^{*}$ \\
\hline UNT & .032 & $.358^{* *}$ & .135 & -.035 & -.002 & $.429^{* *}$ & .022 \\
\hline \multicolumn{8}{|c|}{ Spirituality } \\
\hline REL & -.088 & $.251^{* *}$ & .060 & $-.178^{+}$ & .039 & $.433^{* *}$ & $.650^{* *}$ \\
\hline ES & -.093 & $.408^{* *}$ & -.058 & $-.180^{+}$ & .040 & $.594^{* *}$ & $.301^{* *}$ \\
\hline HAR & -.090 & $.210^{* *}$ & .184 & $-.200^{*}$ & -.101 & $.335^{* *}$ & $.575^{* *}$ \\
\hline TOTAL & -.104 & $.326^{* *}$ & .077 & $-.215^{*}$ & -.006 & $.517^{* *}$ & $.610^{* *}$ \\
\hline
\end{tabular}

Note. ${ }^{+} p<.06 .{ }^{*} p<.05 .{ }^{* *} p<.001$.

SAC - self-acceptance; AFF - affiliation; HEA - health; FS - financial success; IM/P - image/popularity; SPIR - spirituality; COM community feeling; SDT - self-direction-thought; SDA - self-direction-action; ST - stimulation; HE - hedonism; AC - achievement; POD - power-dominance; POR - power-resources; FAC - face; SEP - security-personal; SES - security-societal; TR - tradition; COR - conformity-rules; COI - conformity-interpersonal; HU - humility; BEC - benevolence-caring; BED - benevolence-dependability; UNC - universalism-concern; UNN - universalism-nature; UNT - universalism-tolerance.

The shaded fields show hypothesized relations between variables.

preted as an external confirmation of personal worth, a support for a positive self-valuation and justification for the fulfillment of the need to belong. Thus, caring for respect and social recognition could be logically connected with self-acceptance goals.

The connections between self-direction values and the extrinsic and transcendent goals are more understandable. A lack of money could obstruct freedom of one's actions, so that financial success could be seen as a significant tool to realize the self-direction in action value, as well as the value of stimulation, which was also positively correlated with the pursuit of money. On the other hand, freedom of thought could be expressed through searching for meaning in life and attempts to change the world for the better.

There were also positive correlations between image/popularity goals and valuing tradition and being a reliable and trustworthy member of a group (benevolence-dependability). Maintaining proper image as a goal could be rooted in the belief that one's own group is a value which has to be cultivated. Thus individuals would tend to present adequate signs of being a good in-group member in order to support and strengthen their own group (see Haidt, 2014), which reciprocates and provides protection and identity. 
In addition to the assumed relationships, the spirituality measures also correlated positively with affiliation goals and negatively with the pursuit of financial success. Such configuration supports furthermore the validity of the relevant AI-23 scales. It probably originates in the Polish cultural background, activated by the manner of relating to relevant issues in the instrument which measured spirituality (see Heszen-Niejodek \& Gruszczyńska, 2004). This characteristic of spirituality is in harmony with Catholicism dominating in Poland, which on the one hand highlights the positive role of individuals belonging to larger structures (e.g. the family or nation), and on the other hand (at least officially) diminishes the importance of material goods in personal development and in the process of acquiring happiness in life (see Gospel quotations: Mark 10, 17-22; Mark 10, 23-27; Luke 16, 10-13).

\section{DISCUSSION}

\section{The triangular model of goal contents}

This paper presents an organization of goal contents, which is an alternative to the ones considered previously in the context of self-determination theory (see e.g. Kasser \& Ryan, 1993, 1996; Kasser, 1996; Grouzet et al., 2005; Górnik-Durose \& Janiec, 2010; Zawadzka et al., 2015). In this model the well-established theoretical categories of intrinsic and extrinsic goals are supplemented by an additional category - self-transcendent goals, such as spirituality and community feelings. Such a model fits well with the empirical data we collected.

It is noticeable that in our approach the number of goals and their categories was significantly reduced. Such a reductionist approach could be argued against. Grouzet et al. (2005) sought to extend the range of life goals studied rather than limiting their number. Adding additional goals to the initial seven possibly made the model more elegant, but it did not translate to its improved accuracy. Original goals reflected the intrinsic versus extrinsic orientations sufficiently well, being consistent with the initial assumptions of SDT (Kasser \& Ryan, 1993, 1996). Expanding the range of goals proved to be fruitful only in the case of spirituality.

Giving transcendent goals an equivalent status to the intrinsic and extrinsic could raise objections from the point of view of assumptions underlying SDT. One of its basic principles states that psychological needs of autonomy, competence and relatedness are innate, and their effective realization is accomplished through focus on intrinsic goals (Ryan \& Deci, 2000; Deci \& Ryan, 2008). Extrinsic goals do not interfere with the mental harmony as long as they are perceived as means to achieve intrinsic goals, not ends in themselves (Kasser \& Ahuvia, 2002). In this con- text a question regarding functional importance of self-transcendent goals in the process of fulfilling basic and universal human needs has to be asked.

A classical concept which refers to the universal scope of transcendent needs is the approach proposed by Jung (cf. Dudek, 2002). According to this approach, the individual development of the mental sphere is set to achieve a state of full integration of the psyche. This is possible through contact with representations of archetypical contents, enclosed in the symbols that make up both classical (religion, philosophy, alchemy, gnosticism) and contemporary (science) ways for humans to explore areas beyond their physical functioning. Transcendent needs cannot be easily classified into extrinsic or intrinsic categories. On the one hand, they have an innate character and are a starting point to achieve a state of full integration of the Self. On the other hand, due to the fact that the Self is a component of biological, universal human nature, by definition it contains a collective element.

It is also worth noting that transcendence is a value respected by both religious and secular thinkers. For Thoreau (2004), transcendence was a key concept in understanding reality - transcendence acquired not from epistemological expertise of the nature of things, as he described life not as a cognitive object, but a thing to be lived. Thoreau concluded that when we contemplate Nature deliberately, which is hard work against opinions, prejudices, delusions, and appearances, beyond poetry, philosophy and religion, we will be able to finally examine reality as it is.

Tillich (1948), emphasized the meaning of "the depth" in our lives as a means to break from the routine, from moving in circles and starting over and over again from the same spot, deprived of the desire to look at what is above and under. "The depth" is a transcendent cognitive need which cannot be fully grasped, but is quintessential in achieving the real thoughtfulness in our lives. Similar ideas, although from a naturalistic perspective, appeared in the works of Goodenough and Deacon (2006) and Sagan (1995).

The connections between spirituality and religion with psychological adjustment and well-being have been examined in various studies pointing indifferently to various mediators involved (see e.g. Ellison \& Henderson, 2011; Koenig, McCullough, \& Larson, 2001; Mahoney, Pargament, Swank, \& Tarakeshwar, 2001; Pargament, 1997; Salsman, Brown, Brechting, \& Carlson, 2005), which would confirm the notion about the catalyzing impact of spirituality on intrinsic goals. Conversely, there is a consensus that transcendence and spiritual strivings give deep significance to human existence, which is difficult to explain through other, more basic psychological phenomena (Pargament, 2002). As Emmons $(1999,2005)$ argues, people tend to protect and preserve the sacred, and devote time and effort toward its realization, because even in today's sec- 
ular culture they derive remarkable meaning and purpose from it.

\section{The measure - AI-23}

The proposed version of the Aspiration Index (AI-23) stands out from other questionnaires of this kind in several aspects. It is primarily the most "economical", as it consists of only 23 items, compared with 57 in the AI used by Grouzet et al. (2005) or with 35 in the Polish adaptation by Zawadzka et al. (2015). This seems to be its significant advantage, taking into consideration the expectations of both the respondents and researchers, who tend to apply small or abbreviated questionnaires, sometimes constructed ad hoc, without specifying their psychometric properties other than Cronbach's $\alpha$ (Sheldon, Houser-Marko, \& Kasser, 2006; Sheldon \& Kasser, 2008; Martos \& Kopp, 2012). AI-23 includes the most diagnostic statements, grouped into 7 subscales and 3 domains, whose reliability is in most cases very good. So far the only exception was the self-acceptance scale in the validation studies in the retest sample. It is possible that it fell victim to excessive "psychometric economy", as extending the scales usually helps in stabilizing them. Nevertheless, such an economic approach did not affect the rest of the scales.

However, we do not claim that the proposed model is flawless. It meets "aesthetic" criteria of simplicity and elegance, as well as methodological criteria of dependability and accuracy. Nonetheless, it definitely needs further investigation and confirmation, preferably in studies taking into consideration different cultural backgrounds.

\section{ACKNOWLEDGMENTS}

The authors want to thank the MSc and Ph.D. students who agreed to share their data collected with the AI-PL: Kinga Dziedzic, Dominika Król, Kinga Gregorczyk, Paweł Kot and Magdalena Poraj-Weder. The data were collected in larger survey packages used for other research purposes; however, there is no overlap between the content of this article and any other published work by the above mentioned students. The data were used in the article authored by GórnikDurose and Jach (2016), but there is no overlap between the analyses presented in both articles.

\section{References}

Brown, K. W., \& Kasser, T. (2005). Are psychological and ecological well-being compatible? The role of values, mindfulness, and lifestyle. Social Indicators Research, 74, 349-368. doi: 10.1007/s11205004-8207-8
Brown, T. A. (2006). Confirmatory factor analysis for applied research. New York: Guilford Press.

Cieciuch, J. (2013). Pomiar wartości w zmodyfikowanym modelu Shaloma Schwarza [The measurement of values in the redefined Schwartz's theory]. Psychologia Spoteczna, 24, 22-41.

Comte-Sponville, A. (2009). The Book of Atheist Spirituality. An elegant argument for spirituality without God. London: Bantam Press.

Deci, E. L., \& Ryan, R. M. (2007). Facilitating Optimal Motivation and Psychological Well-Being Across Life's Domains. Canadian Psychology, 49, 14-23. doi: 10.1037/0708-5591.49.1.14

Deci, E. L., \& Ryan, R. M. (2008). Self-Determination Theory: A Macrotheory of Human Motivation, Development and Health. Canadian Psychology, 49, 182-185. doi: 10.1037/a0012801

Dudek, Z. W. (2002). Podstawy psychologii Junga [The basics of Jungian psychology]. Warszawa: Eneteia.

Ecklund, E. H., \& Long, E. (2011). Scientists and Spirituality. Sociology of Religion, 72, 253-274. doi: $10.1093 /$ socrel/srr003

Ellison, C. G., \& Henderson, A. K. (2011). Religion and mental health: Through the lens of the stress process. In A. Blasi (Ed.), Toward a sociological theory of religion and health (pp. 11-44). Holland: Brill. doi: 10.1163/ej.9789004205970.i-277.7

Emmons, R. A. (1999). The Psychology of Ultimate Concerns: Motivation and Spirituality in Personality. New York: The Guilford Press.

Emmons, R. A. (2005). Striving for the Sacred: Personal Goals, Life Meaning, and Religion. Journal of Social Issues, 61, 731-745. doi: 10.1111/j.15404560.2005.00429.x

Emmons, R. A., Cheung, C., \& Tehrani, K. (1998). Assessing spirituality through personal goals Implications for research on religion and subjective well-being. Social Indicators Research, 45, 391-422. doi: 10.1023/A:1006926720976

Goodenough, U., \& Deacon, T. W. (2006). The Sacred Emergence of Nature. In P. Clayton (Ed.), Oxford Handbook of Science and Religion (pp. 853-871). New York: Oxford University Press. doi: 10.1093/ oxfordhb/9780199543656.003.0051

Górnik-Durose, M., \& Janiec, K. (2010). Merkantylizm psychiczny, struktura celów życiowych a poczucie dobrostanu psychicznego [Psychological merchantilism, the structure of life goals and psychological well-being]. In A. M. Zawadzka \& M. Górnik-Durose (Eds.), Życie w konsumpcji, konsumpcja w życiu. Psychologiczne ścieżki wspótzależności [Life in consumption, consumption in life. Psychological paths of interdependence] (pp. 142-160). Sopot: GWP.

Górnik-Durose, M. E., \& Jach, Ł. (2016). The structure of goal contents revisited. A verification of the model in Polish samples. Polish Psychological Bulletin, 47, 451-463. 
Górnik-Durose, M. E., Jach, Ł., Sikora,T., \& Wojtyna, E. (2013). "What do you think when you think about health?” - understanding health in the modern world. Paper presented at the EHPS Conference, Bordeaux, 16-20.07.2013.

Grouzet, M. E., Ahuvia, A., Kim, Y., Ryan, R. M., Schmuck, P., Kasser, T., ...Sheldon, K. M. (2005). The Structure of Goal Contents Across 15 Cultures. Journal of Personality and Social Psychology, 89, 800-816. doi: 10.1037/0022-3514.89.5.800

Haidt, J. (2014). Prawy umyst [The Righteous Mind]. Sopot: Smak Słowa.

Heszen-Niejodek, I., \& Gruszczyńska, E. (2004). Wymiar duchowy człowieka, jego znaczenie w psychologii zdrowia i jego pomiar [Spirituality as a human dimension, its importance in health psychology, and its measurement]. Przeglad Psychologiczny, 47, 15-31.

Hu, L. T., \& Bentler, P. M. (1999). Cutoff Criteria for Fit Indexes in Covariance Structure Analysis: Conventional Criteria Versus New Alternatives. Structural Equation Modeling, 6, 1-55. doi: 10.1080/10705519909540118

Kasser, T. (1996). Aspirations and Well-Being in Prison Setting. Journal of Applied Social Psychology, 26, 1367-1377. doi: 10.1111/j.1559-1816.1996.tb00076.x

Kasser, T. (2002). The high price of materialism. Cambridge, MA: MIT Press.

Kasser, T., \& Ahuvia, A. (2002). Materialistic values and well-being in business students. European Journal of Social Psychology, 32, 137-146. doi: 10.1002/ejsp.85

Kasser, T., \& Ryan, R. M. (1993). A dark side of the American dream: correlates of financial success as a central life aspiration. Journal of Personality and Social Psychology, 65, 410-422. doi: 10.1037/00223514.65.2.410

Kasser, T., \& Ryan, R. M. (1996). Further examining the American dream: Differential correlates of intrinsic and extrinsic goals. Personality and Social Psychology Bulletin, 22, 280-287. doi: 10.1177/0146167296223006

Kilbourne, W., Grunhagen, M., \& Foley, J. (2005). A cross-cultural examination of the relationship between materialism and individual values. Journal of Economic Psychology, 26, 624-641. doi: 10.1016/j.joep.2004.12.009

Kim, Y., Kasser, T., \& Lee, H. (2003). Self-concept, aspirations, and well-being in South Korea and the United States. Journal of Social Psychology, 143, 277-290. doi: 10.1080/00224540309598445

Koenig, H. G., McCullough, M. E., \& Larson, D. B. (2001). Handbook of religion and health. Oxford: Oxford University Press.

Mahoney, A., Pargament, K., Swank, A., \& Tarakeshwar, N. (2001). Religion in the home in the 1980s and 1990s: A meta-analytic review and conceptual anal- ysis of links between religion, marriage, and parenting. Journal of Family Psychology, 15, 559-596.

Martos, T., \& Kopp, M. S. (2012). Life goals and well-being: Does financial status matter? Evidence from a representative Hungarian sample. Social Indicator Research, 105, 561-568.

Niemiec, C. P., Ryan, R. M., Deci, E. L., \& Williams, G. C. (2009). Aspiring to physical health: The role of aspirations for physical health in facilitating long-term tobacco abstinence. Patient Education and Counseling, 74, 250-257. doi: 10.1016/j. pec.2008.08.015

Nunnally, J., \& Bernstein, I. (1994). Psychometric theory. New York: McGraw-Hill.

Pargament, K. I. (1997). The psychology of religion and coping: Theory, research, practice. New York: Guilford Press.

Pargament, K. I. (2002). Is religion nothing but...? Explaining religion versus explaining religion away. Psychological Inquiry, 13, 239-244. doi: 10.1207/ S15327965PLI1303_06

Ryan, R. M., \& Deci, E. L. (2000). Self-determination Theory and the Facilitation of Intrinsic Motivation, Social Development, and Well-Being. American Psychologist, 55, 68-78. doi: 10.1037/0003066X.55.1.68

Sagan, C. (1995). Wonder and skepticism. Skeptical Inquirer, 19, 24-30.

Salsman, J. M., Brown, T. L., Brechting, E. H., \& Carlson, C. R. (2005). The link between religion and spirituality and psychological adjustment: The mediating role of optimism and social support. Personality and Social Psychology Bulletin, 31, 522-535. doi: 10.1177/0146167204271563

Schermelleh-Engel, K., Moosbrugger, H., \& Müller, H. (2003). Evaluating the Fit of Structural Equation Models:Tests of Significance and Descriptive Goodness-of-Fit Measures. Methods of Psychological Research Online, 8, 23-74.

Schmidt, L. E. (2005). Restless Souls: The Making of American Spirituality. New York.

Schmuck, P., Kasser, T., \& Ryan, R. M. (2000). The relationship of well-being to intrinsic and extrinsic goals in Germany and the U.S. Social Indicators Research, 50, 225-241. doi: 10.1023/A:1007084005278

Schwartz, S. H. (1992). Universals in the content and structure of values: Theoretical Advancesand empirical tests in 20 countries. In M. Zanna (Ed.), Advances in experimental social psychology (Vol. 25, pp. 1-65). London: Academic Press.

Schwartz, S. H., Cieciuch, J., Vecchione, M., Davidov, E., Fischer, R., Beierlein, C., ...Konty, M. (2012). Refining the theory of basic individual values. Journal of Personality and Social Psychology, 103, 663-688. doi: 10.1037/a0029393

Sheldon, K., Houser-Marko, L., \& Kasser, T. (2006). Does autonomy increase with age? Comparing the goal motivations of college students and their par- 
ents. Journal of Research in Personality, 40, 168-178. doi: 10.1016/j.jrp.2004.10.004

Sheldon, K., \& Kasser, T. (2008). Psychological threat and extrinsic goal striving. Motivation and Emotion, 32, 37-45. doi: 10.1007/s11031-008-9081-5

Solomon, R. C. (2002). Spirituality for the Skeptic: The Thoughtful Love of Life. New York: Oxford University Press.

Thoreau, H. D. (2004). Walden: A Fully Annotated Edition. New Haven: Yale University Press.

Tillich, P. (1948). The Depth of Existence. The Shaking of the Foundations. New York: Scribners.

Truong, Y., \& McColl, R. (2011). Intrinsic motivations, self-esteem, and luxury goods consumption. Journal of Retailing and Consumer Services, 18, 555561. doi: 10.1016/j.jretconser.2011.08.004

Vansteenkiste, M., Duriez, B., Simons, J., \& Soenens, B. (2006). Materialistic Values and Well-Being Among Business Students: Further Evidence of Their Detrimental Effect. Journal of Applied Social Psychology, 36, 2892-2908. doi: 10.1111/j.00219029.2006.00134.x

Zawadzka, A. M., Duda, J., Rymkiewicz, R., \& Kondratowicz-Nowak, B. (2015). Siedmiowymiarowy model aspiracji życiowych Kassera i Ryana: analiza trafności i rzetelności narzędzia [Seven-dimensional model of life aspirations by Kasser and Ryan: Analysis of validity and reliability of the instrument]. Psychologia Spoteczna, 1, 100-111. doi: 10.7366/1896180020153207 